\title{
Cot deaths, stillbirths, and the probation service: a potentially recognisable at risk group
}

\author{
E J PUGH, R STATHAM, AND S JARVIS
}

Darlington Health Authority, Memorial Hospital, Darlington, Cleveland Probation Service, Middlesbrough, and Department of Child Health, Medical School, University of Newcastle upon Tyne

SUMMARY Families of clients under the care of the probation service are at significantly higher risk of experiencing a cot death or a stillbirth than the general public. Pregnant women in the immediate families of clients under the care of the probation service should be identified to health service personnel involved in their antenatal and postnatal care in an effort to avert unnecessary deaths.

The present study was undertaken to ascertain whether sudden infant death syndrome was more common in infants whose parents were under the care of the probation service. This followed a casual enquiry from a probation officer to one of us (EP) for information regarding cot death as several cases had been noted within the local service over the preceding year.

The work of the probation service is predominantly with offenders and their families. Home Office probation statistics for 1984 revealed that nationally some 147000 people were under the care of the probation service on the census day (31 December 1984). Of those being supervised, $82 \%$ were men, $53 \%$ of whom were aged between 17 and 29 years. About half the women being supervised were also aged between 17 and 29 years. The types of offences committed by those beginning probation have changed little over the last five years, with Home Office statistics revealing that roughly a half of the clients had been found guilty of theft, with another $7 \%$ convicted for violence against the person.

A search of the publications revealed little information about the health of persons on probation. One study suggested that as many as $10 \%$ of clients of the probation service may be receiving psychiatric treatment. ${ }^{1}$ A sizable number of youth who enter the judicial system each year may be at risk of psychiatric disability. ${ }^{2}$ A physical examination of 233 juvenile delinquents on a comprehensive probation programme found most in poor health. ${ }^{3}$ No studies could be found concerning the outcome of pregnancies among clients on probation nor about the health of the clients' children.
In England and Wales there are about 1300 'sudden infant deaths' in the first year of life, ${ }^{4}$ representing about one third of the annual total of deaths after the neonatal period. A recent multicentre study showed evidence of an increased risk of infant death in lower social class families, with more children having more family problems and living in less satisfactory housing. ${ }^{5}$ Family and community factors associated with potentially preventable infant deaths were identified by Taylor and Emery. ${ }^{6}$ These included domestic, financial, and housing problems, parental health, parental intelligence and competence, and family circumstances. ${ }^{6}$ Studies of women addicted to opiates have shown high incidences, ${ }^{7}$ barbiturates also having been implicated. ${ }^{8}$ The suspicion of filicide (child homicide by either parent) may be a major factor in between $2 \%$ and $10 \%$ of unexplained cot deaths. ${ }^{9}{ }^{10}$ Attempts have been made to create a scoring system to identify infants at risk of 'unexpected death', using combinations of various factors present at the birth of the child. Their use, however, remains controversial; the multicentre study acknowledged the discriminatory power of the at birth risk scoring system of Carpenter $e$ al $^{11}$ but remarked on its low sensitivity and specificity. ${ }^{5}$ The cost-benefit ratio of scoring systems also remains an area of debate. ${ }^{12}$

A client group comprising those on probation has an undoubted preponderance of the factors associated with high incidence of cot deaths. High risk at birth scores could be expected from such mothers.

\section{Methods}

The initial study was conducted in the Cleveland 
probation service in April 1985. All probation officers in the service were asked to review their records to provide details of the number of births and cot deaths that occurred to female clients on probation or to the wife, common law wife, or girlfriend of a male client on probation during the calendar year 1984.

After the initial results a second survey was deemed appropriate; four other probationary areas were approached in November 1985 to obtain similar basic data to the initial study, including the number of stillbirths for the calendar year 1985. A standardised simple questionnaire was circulated to all probation officers for completion.

\section{Results}

Three of the four probation services responded to the second survey. Results from both surveys are shown in Tables 1 and 2 . Five cots deaths were identified from Humberside, Northumberland, and Durham, with an overall rate of 13.5 per 1000 births (one in 73 live births). Numbers of stillbirths were returned from the initial survey, though they were not requested; the second survey specifically requested stillbirth figures. The initial Cleveland survey revealed a stillbirth rate of 44 per 1000 births and the second survey a rate of 24 per 1000 births.

Table 1 No of births, cot deaths, and stillbirths occurring to female clients or to wives, common law wives, or girlfriends of male clients on probation in four probation districts

\begin{tabular}{lllll}
\hline $\begin{array}{l}\text { Probation } \\
\text { district }\end{array}$ & Year & $\begin{array}{l}\text { Births } \\
\text { (estimated) }\end{array}$ & Cot deaths & Stillbirths \\
\hline Humberside & 1985 & 113 & $4^{*}$ & 3 \\
Northumbria & 1985 & 185 & 1 & 3 \\
Durham & 1985 & 72 & 0 & 3 \\
Cleveland & 1984 & 68 & 3 & $3 \dagger$ \\
\hline Total & & 438 & 8 & 12 \\
\hline
\end{tabular}

*One was a filicide.

†Information received but not requested

Table 2 Rates/1000 births of cot deaths and stillbirths for clients on probation compared with national figures

\begin{tabular}{llll}
\hline & \multicolumn{2}{l}{ Rates/1000 births } \\
\cline { 2 - 4 } & $\begin{array}{l}\text { Probation } \\
\text { survey }\end{array}$ & $\begin{array}{l}\text { National } \\
(1984)\end{array}$ & $\begin{array}{l}\text { Relative } \\
\text { risk }\end{array}$ \\
\hline Cot death & $18 \cdot 2^{*}$ & 1.95 & $9 \cdot 4$ \\
Stillbirth & $27 \cdot 4^{* *}$ & $5 \cdot 7$ & $4 \cdot 8$ \\
\hline
\end{tabular}

${ }^{*} \chi^{2}$ (with Yates's correction) $=50 \cdot 1, \mathrm{p}<0 \cdot 001$ (excluding Cleveland $\chi^{2}=19 \cdot 5$, $\mathrm{p}<0 \cdot 001)$.

${ }^{* *} \chi^{2}$ (with Yates's correction) $=34 \cdot 5, p<0.001$ (excluding Cleveland $\chi^{2}=20 \cdot 7$, $\mathrm{p}<0.001)$.

\section{Discussion}

Families of clients under the care of the probation service are at significantly higher risk of experiencing a cot death or a stillbirth than the general public. Indeed these results suggest that about one in 20 pregnancies in the families of clients under the care of the probation service might have such a fatal outcome. Reasons for this are likely to be multifactorial, with physical, social, and psychological factors all probably implicated.

Confidentiality is respected about being 'on probation', and health service workers will not usually be aware that a person is on probation. At present in Cleveland no extra health service input is aimed directly at this client group. On the other hand, the probation service seems to see a high risk client group for which the need for the intervention of the health service would seem to be great. Pregnant women in the immediate families of clients under the care of the probation service should be notified to the health service personnel involved in their antenatal and postnatal care in an effort to avert unnecessary deaths.

Thanks must be extended to the chief probation officers, without whose cooperation the study would not have been possible; thanks are also due to the individual probation officers for their work in supplying the data.

\section{References}

' Bowden P. A psychiatric clinic in a probation office. $\mathrm{Br} J$ Psychol 1978;133:448-51.

2 Halpern EI, Arkins V, Mitchell N, Freeling N, Healy B. Continuity of mental health care to youth in the juvenile justice network. Hospital and Community Psychology 1981;32:114-7.

3 Chaiklin H, Chesley FD, Litsinger WC Jr. Delinquency and health status. Health Soc Work 1977;3,24-37.

4 Office of Population Censuses and Surveys. Sudden infant death syndrome. Series DH3. London: HMSO, 1983, 1984.

${ }^{5}$ Knowelden J, Keeling J, Nichol J. Report of a multicentre study of postneonatal mortality. London: HMSO, 1984.

6 Taylor EM, Emery JL. Family and community factors associated with infant deaths that might be preventable. $\mathrm{Br}$ Med $J$ 1983;287:871-4.

7 Golding J, Limerick S, Macfarlane A. Sudden infant death: patterns puzzles and problems. Shepton Mallet, Somerset: Open books, 1985:57-8.

${ }^{8}$ Naeye RL, Ladis B, Drage JS. Sudden infant death syndrome: a prospective study. Am J Dis Child 1976;130:1207-10.

9 Anonymous. Cot death: the unfounded lurking suspicion [Editorial]. Lancet 1984;ii:1137.

10 Emery JL. Infanticide, filicide and cot deaths. Arch Dis Child 1985;60:505-7.

11 Carpenter RG, Gardner A, McWeeny PM, Emery JL. Multistage scoring systems for identifying infants at risk of unexpected deaths. Arch Dis Child 1977;52:606-12.

12 Forbes JF. Preventing cot deaths. Lancet 1985;i:930-1.

Correspondence to Dr E J Pugh, Wellhouse, East View, Sadberge, Co Durham DL2 1FF, England.

Received 23 April 1986 